\title{
LIBERDADE DE EXPRESSÃO: ALGUMAS PONDERAÇõES EM MATÉRIA PENAL À LUZ DA CONSTITUIÇÃO FEDERAL DO BRASIL
}

\section{FREEDOM OF SPEECH: SOME REMARKS IN CRIMINAL LAW BASED ON THE BRAZILIAN CONSTITUTION}

Ingo Wolfgang Sarlet ${ }^{1}$ Jayme Weingartner Neto ${ }^{2}$

Resumo: No presente artigo discute-se o conteúdo e os limites da liberdade de expressão na ordem jurídico-constitucional brasileira, em especial o problema das suas implicações em matéria criminal. Sustenta-se que o elemento da tipicidade penal em especial nos delitos contra a honra e a imagem deve ser interpretado de modo restritivo e levando em conta o peso da liberdade de expressão para o Estado Democrático.

Palavras-chave: Liberdade de expressão. Limites. Direito penal. Interpretação restritiva.

\begin{abstract}
This paper discusses the content and the limits of freedom of speech within the Brazilian legal and constitutional order, focusing the problem of its implications in the domain of criminal law. It is sustained that the definition of a crime should be interpreted in a restrictive way and considering the weight of freedom of speech for a democratic state. Keywords: Freedom of speech. Content and limits. Criminal law. Restrictive interpretation.
\end{abstract}

\footnotetext{
Pós-Doutor pela Ludwig-Maximilians-Universität München, Alemanha; Doutor em Direito pela Ludwig Maximillians Universität München, Alemanha; Professor Titular da Faculdade de Direito e dos Programas de Mestrado e Doutorado em Direito e em Ciências Criminais da Pontifícia Universidade Católica do Rio Grande do Sul; Avenida Ipiranga, 6681, Partenon, Porto Alegre, Rio Grande do Sul, Brasil; iwsarlet@gmail.com

2 Doutor em Direito do Estado pela Pontifícia Universidade Católica do Rio Grande do Sul; Mestre em Ciências Jurídico-Criminais pela Universidade de Coimbra; Professor no Mestrado em Direito da Universidade LaSalle Canoas; Desembargador do Tribunal de Justiça; jwneto@tj.rs.gov.br
} 


\section{Notas introdutórias}

Diferente de outras ordens constitucionais (Portugal, Espanha e Itália, por exemplo), a Constituição Federal de 1988 (doravante referida apenas como CF) não adotou o termo liberdade de expressão como o gênero que abarca as diversas manifestações específicas, como a livre manifestação do pensamento, a liberdade de consciência e de crença, a liberdade de comunicação (incluindo a liberdade de imprensa) e a livre expressão artística, intelectual e científica. Todavia, é possível considerar a livre manifestação do pensamento como assumindo tal condição (cláusula geral em matéria de liberdade de expressão), visto que a manifestação do pensamento poderá ocorrer na esfera da comunicação social, no exercício da atividade intelectual ou artística, ou mesmo dizer respeito à livre manifestação das opções religiosas.

Embora se possa afirmar que foi apenas sob a égide da CF que as liberdades de expressão encontraram o ambiente propício para a sua efetivação (KOATZ, 2011, p. 391 e ss.), é preciso registrar que tais liberdades se fazem presentes na trajetória constitucional brasileira desde a Carta Imperial de 1824, vivenciando períodos de maior ou menor limitação, como ocorreu no contexto da assim chamada Ditadura do Estado Novo, cuja Constituição (1937) estabelecia fortes limitações ao exercício da liberdade de expressão, mas também como ocorreu no período da Ditadura Militar de 1964-1985.

Por outro lado, embora não seja o caso de aqui ser explorada tal vereda, importa destacar que, ressalvadas eventuais peculiariedades, a CF guarda sintonia com a evolução registrada, notadamente a contar da Declaração Universal dos Direitos Humanos da ONU, de 1948, no âmbito do direito internacional dos direitos humanos. Assim, apenas para referir os documentos mais importantes, com ênfase, além da Declaração Universal, nos principais tratados ratificados pelo Brasil, verifica-se que de acordo com o artigo 19 da Declaração, "todo o indivíduo tem direito à liberdade de opinião e de expressão, o que implica o direito de não ser inquietado pelas suas opiniões e o de procurar, receber e difundir, sem consideração de fronteiras, informações e idéias por qualquer meio de expressão." Já o Pacto Internacional dos Direitos Civis e Políticos, de 1966, ratificado pelo Brasil, mediante sua incorporação ao direito interno em 1992, dispõe no seu artigo 19.1 que

ninguém poderá ser molestado por suas opiniões. 2. Toda pessoa terá direito à liberdade de expressão; esse direito incluirá a liberdade de procurar, receber e difundir informações e ideias de qualquer natureza, independentemente de considerações de fronteiras, verbalmente ou por escrito, em forma impressa ou artística, ou qualquer outro meio de sua escolha.

Por derradeiro, cita-se o artigo 13.1 da Convenção Americana de Direitos Humanos (Pacto de São José da Costa Rica) - igualmente ratificada pelo Brasil -, de acordo com o qual

toda pessoa tem o direito à liberdade de pensamento e de expressão. Esse direito inclui a liberdade de procurar, receber e difundir informações e ideias de qualquer 
natureza, sem considerações de fronteiras, verbalmente ou por escrito, ou em forma impressa ou artística, ou por qualquer meio de sua escolha $[. .$.

Também no plano europeu, embora não se trate de uma normativa vinculante para o caso brasileiro, registra-se uma forte proteção da liberdade de expressão e de manifestação, com uma preferência evidente pela fórmula genérica da liberdade de expressão, como apresenta o artigo 10.1 da Convenção Europeia de Direitos Humanos ("Qualquer pessoa tem direito à liberdade de expressão. Este direito compreende a liberdade de opinião e a liberdade de receber ou de transmitir informações ou ideias sem que possa haver ingerência de quaisquer autoridades públicas e sem considerações de fronteiras [...]"), bem como o artigo 11.1 da Carta de Direitos Fundamentais da União Europeia ("Todas as pessoas têm direito à liberdade de expressão. Este direito compreende a liberdade de opinião e a liberdade de receber e de transmitir informações ou ideias, sem que possa haver ingerência de quaisquer poderes públicos e sem consideração de fronteiras"), que, por força da entrada em vigor do Tratado de Lisboa, o qual integra, na condição de catálogo europeu de direitos fundamentais, passou a vincular os países integrantes da União Europeia.

No âmbito da trajetória do direito constitucional estrangeiro, a liberdade de expressão (manifestação do pensamento) encontrou guarida já na primeira onda do constitucionalismo moderno, figurando, por exemplo, tanto no catálogo de direitos acrescido pela primeira leva de emendas constitucionais à Constituição Norte-Americana, em 1791, quanto nas primeiras constituições da França revolucionária, por influência da própria Declaração dos Direitos do Homem e do Cidadão, de 1789, em que fora consagrada expressamente no artigo 11, tendo, antes disso, sido já prevista na Declaração de Direitos da Inglaterra, de 1689, bem como em documentos similares.

A atual configuração do conteúdo e alcance da liberdade de expressão, seja nos Estados Unidos, seja na Alemanha ou no Brasil (aliás, seja onde for), para além do teor literal dos enunciados do direito constitucional positivo ou dos textos que integram os sistemas supranacionais de proteção dos direitos humanos, é o resultado (sempre dinâmico) de um complexo processo de regulação estatal (não apenas legislativa) e de (re)construção doutrinária e jurisprudencial.

Não obstante uma série de aspectos comuns na experiência ocidental, diferenças relevantes podem ser apontadas, não apenas no que diz com o âmbito de proteção da liberdade de expressão, mas também com os seus limites, incluindo o modo pelo qual o exercício da liberdade de expressão se conexiona com outros bens constitucionalmente relevantes. Para ilustrar a afirmação, bastaria lembrar as lutas sociais, os protestos por melhorias socioeconômicas e demandas por reconhecimento por minorias, bem como as novas possibilidades e ameaças advindas do desenvolvimento exponencial da tecnociência, nomeadamente ao desembocar no que se convencionou chamar de sociedade digital.

Mesmo por sua natural vocação de tutela subsidiária de bens jurídicos, o direito penal acaba sendo um entreposto valorativo e implica uma primeira tomada de posição em relação aos vários bens emaranhados. Assim, é de indagar o efetivo âmbito de proteção da liberdade de expressão e 
em que medida nessa seara se faz presente um regime especial para as hipóteses de conflitos entre a liberdade de expressão e outros direitos, interesses e valores com suporte constitucional, v.g., honra, privacidade, probidade administrativa e transparência pública.

É nessa perspectiva, da concretização da liberdade de expressão e sua tensão na seara penal, que no presente texto se objetiva apresentar e comentar, postas as premissas constitucionais e a caracterização da liberdade de expressão como direito fundamental na CF, uma questão ilustrativa atinente a crimes contra a honra, plasmados pela figura da crítica objetiva de interesse público. A hipótese que se formula e pretende demonstrar é que as figuras delitivas que envolvem os crimes contra a honra devem ser interpretadas de modo restritivo, salvaguardando a liberdade de expressão, designadamente de acordo com a baliza da crítica objetiva e afinada com o interesse público, que, demonstrada no caso concreto, afasta o elemento da tipicidade.

\section{A liberdade de expressão como direito fundamental}

\subsection{Aspectos gerais}

No âmbito da CF, as liberdades de expressão (ou liberdades comunicativas) foram, não apenas foram objeto de mais detalhada positivação, mas também passaram a corresponder, pelo menos de acordo com Texto Constitucional, ao patamar de reconhecimento e proteção compatível com um autêntico Estado Democrático de Direito. Com efeito, apenas para ilustrar tal assertiva mediante a indicação dos principais dispositivos constitucionais sobre o tema, já no artigo $5^{\circ}$, IV, foi solenemente enunciado que "é livre a manifestação do pensamento, sendo vedado o anonimato." Tal dispositivo, que, é possível arriscar, faz as vezes, no caso brasileiro, de uma espécie de cláusula geral, foi complementado e guarda relação direta com uma série de outros dispositivos da Constituição, os quais, no seu conjunto, formam o arcabouço jurídico-constitucional que reconhece e protege a liberdade de expressão nas suas diversas manifestações. Assim, logo no dispositivo seguinte, art. $5^{\circ}$, V, "é assegurado o direito de resposta, proporcional ao agravo, além da indenização por dano material, moral ou à imagem." No inciso VI do mesmo artigo consta que "é inviolável a liberdade de consciência e de crença, sendo assegurado o livre exercício dos cultos religiosos e garantida, na forma da lei, a proteção aos locais de culto e suas liturgias. ${ }^{3}$ De alta relevância para a liberdade de expressão é o artigo $5^{\circ}$, IX, de acordo com o qual "é livre a expressão da atividade intelectual, artística, científica e de comunicação, independentemente de censura ou licença.

Dentre os dispositivos diretamente relacionados com a liberdade de expressão, situam-se diversos enunciados dispersos na Constituição, alguns formulados de modo a assegurar expressa-

3 Tal dispositivo foi complementado pelos incisos VII e VIII do artigo $5^{\circ}$, voltados à proteção, mas também à delimitação, da liberdade religiosa e de consciência. 
mente direitos de liberdade da pessoa humana. É o caso, por exemplo, do artigo 206, II, que dispõe sobre a liberdade de aprender, ensinar, pesquisar e divulgar o pensamento, a arte e o saber, no âmbito das diretrizes do ensino. Já no artigo 220, no capítulo da comunicação social, está consignado que a manifestação do pensamento, a criação, a expressão e a informação, sob qualquer forma, processo ou veículo, não sofrerão qualquer restrição, observado o disposto nesta Constituição.

Tais exemplos não esgotam o elenco de disposições constitucionais relacionadas com a liberdade de expressão, mas já demonstram o lugar de destaque e o alto nível de proteção que tais liberdades experimentam na atual CF, devendo ser objeto de referência e algum desenvolvimento no momento oportuno, quando for o caso. Por outro lado, considerando algumas peculiaridades da liberdade de consciência e de crença, assim como da liberdade artística, das liberdades de ensino e pesquisa, bem como das liberdades de reunião e manifestação, tais direitos não serão aqui objeto de análise.

\subsection{Conteúdo da Liberdade de Expressão: uma definição inclusiva}

Consoante já adiantado, optou-se por utilizar o termo genérico liberdade de expressão como noção que abrange tanto a livre manifestação do pensamento prevista no artigo $5^{\circ}$, inciso IV, da CF, quanto outras dimensões da liberdade de expressão. A liberdade de expressão, portanto, como o sugeriu Machado (2002, p. 370 e ss.), será aqui tratada como uma espécie de "direito mãe", refutando-se uma abordagem compartimentada, como alguns costumam estabelecer entre as liberdades de comunicação e de expressão, conforme sugere parte da literatura especializada, ${ }^{4}$ muito embora existam diferenças (seja no que diz respeito ao âmbito de proteção, seja no concernente aos limites e restrições) entre as diversas manifestações da liberdade de expressão consideradas especificamente, como é o caso da liberdade de expressão artística, científica, liberdade de imprensa, liberdade de informação, entre outras.

Por tal razão, as diversas posições fundamentais vinculadas à liberdade de expressão serão analisadas não como um mero conglomerado, mas como partes interligadas de uma concepção geral, que reclama uma abordagem sistemática e integrada, preservadas, todavia, as peculiaridades de cada direito fundamental em espécie (FECHNER, 2010, p. 530).

É amplamente reconhecido que a liberdade de expressão constitui um dos direitos fundamentais mais preciosos e integra os catálogos constitucionais desde a primeira fase do constitucionalismo moderno. Assim como a liberdade de expressão encontra um dos seus principais fundamentos (e objetivos) na dignidade da pessoa humana, naquilo em que diz respeito à autonomia e livre desenvolvimento da personalidade do indivíduo, ela também guarda relação, em uma dimensão social

\footnotetext{
4 Cf., por exemplo, a senda trilhada, no caso da literatura especializada brasileira, por Farias (2004, p. 52 e ss.), muito embora o necessário registro de que o autor também sustenta um âmbito de proteção amplo de ambas as liberdades, apresentando um leque minucioso de posições jurídicas por elas abrangidas.
} 
e política, com as condições e a garantia da democracia e do pluralismo político, assegurando uma espécie de livre mercado das ideias, assumindo, nesse sentido, a qualidade de um direito político e revelando ter também uma dimensão nitidamente transindividual, ${ }^{5}$ já que a liberdade de expressão e seus respectivos limites operam essencialmente na esfera das relações de comunicação e da vida social.

Quanto a esse aspecto, ainda que de modo sintético, importa sublinhar que a relação entre democracia e liberdade de expressão é de um recíproco condicionamento e assume um caráter complementar, dialético e dinâmico, de modo que embora mais democracia possa muitas vezes significar mais liberdade de expressão e vice-versa (mais liberdade de expressão indica mais democracia), também é correto que a liberdade de expressão pode acarretar riscos para a democracia e esta para a liberdade de expressão (MICHELMAN, 2007, p. 49 e ss.).

Já pelas razões articuladas - para que a liberdade de expressão possa cumprir sua função em uma ordem democrática e plural - é de sublinhar que quanto ao seu âmbito de proteção, a liberdade de expressão abarca um conjunto diferenciado de situações, cobrindo, em princípio, uma série de liberdades (faculdades) de conteúdo espiritual, incluindo expressões não verbais, como é o caso da expressão musical, da comunicação pelas artes plásticas, entre outras (MICHAEL; MORLOK, 2008, p. 126). A liberdade de expressão consiste, mais precisamente, na liberdade de exprimir opiniões, ou seja, juízos de valor a respeito de fatos e ideias, portanto, juízos de valor sobre opiniões de terceiros, etc. (EPPING, 2007, p. 86). Assim, é a liberdade de opinião que se encontra na base de todas as modalidades da liberdade de expressão, ${ }^{6}$ de modo que o conceito de opinião (que, na linguagem da $\mathrm{CF}$, acabou sendo equiparado a de pensamento) há de ser compreendido em sentido amplo, de forma inclusiva, abarcando, também, apenas para deixar mais claro, manifestações a respeito de fatos e não apenas juízos de valor (MICHAEL; MORLOK, 2008, p. 128). Importa acrescentar que, além da proteção do conteúdo, ou seja, do objeto da expressão, também estão protegidos os meios de expressão, cuidando-se, em qualquer caso, de uma noção aberta, portanto inclusiva de novas modalidades, como é o caso da comunicação eletrônica. ${ }^{7}$

Para assegurar a sua máxima proteção e sua posição de destaque no âmbito das liberdades fundamentais, o âmbito de proteção da liberdade de expressão deve ser interpretado como o mais extenso possível, englobando tanto a manifestação de opiniões quanto de ideias, pontos de vista, convicções, críticas, juízos de valor sobre qualquer matéria ou assunto e mesmo proposições a respei-

\footnotetext{
5 Nesse sentido, v., por todos, Machado (2002, p. 237 e ss.), que atribui à liberdade de expressão um caráter essencialmente instrumental, portanto, não de um fim em si mesmo.

6 Cf. Silva (2007, p. 241), a liberdade de opinião "resume a própria liberdade de pensamento em suas várias formas de expressão. Por isso é que a doutrina a chama de liberdade primária e ponto de partida das outras. Trata-se da liberdade de o indivíduo adotar a atitude intelectual de sua escolha: quer um pensamento íntimo, quer seja a tomada de posição pública; liberdade de pensar e dizer o que se crê verdadeiro." Para o autor, aderindo a uma conceituação ampla, a liberdade de opinião "se exterioriza pelo exercício das liberdades de comunicação, de religião, de expressão intelectual, artística, científica, cultural e de transmissão e recepção do conhecimento." (SILVA, 2007, p. 243).

7 Cf. Canotilho e Moreira (2007, p. 572), adotando uma concepção ampliada do âmbito de proteção da liberdade de expressão.
} 
to de fatos (CANOTILHO; MOREIRA, 2007, p. 572). ${ }^{8}$ Nesse sentido, em princípio todas as formas de manifestação, desde que não violentas, estão protegidas pela liberdade de expressão, incluindo "gestos, sinais, movimentos, mensagens orais e escritas, representações teatrais, sons, imagens, bem como as manifestações veiculadas pelos modernos meios de comunicação, como as mensagens de páginas de relacionamento, 'blogs', etc." (KOATZ, 2011, p. 399). ${ }^{9}$

Uma compreensão elástica do âmbito de proteção esbarra, todavia, em algumas questões polêmicas, como, por exemplo, a negativa de fatos históricos ou mesmo no que diz com a existência de um dever de verdade quanto aos fatos, bem como no tocante aos assim chamados delitos de opinião, visto que nesses casos se verifica maior controvérsia sobre a sua inclusão no âmbito de proteção da liberdade de expressão. Quanto a tais questões, adota-se aqui a linha de entendimento sustentada por Canotilho e Moreira (2007, p. 572), ao negarem a existência de um dever de verdade quanto aos fatos, bem como ao afastarem, em princípio, qualquer tipo de "delito de opinião", ainda que se cuide de opiniões que veiculem posições contrárias à ordem constitucional democrática, ressalvando, contudo, que eventuais distorções dos fatos e manifestações que atinjam direitos fundamentais e interesses de terceiros e que representem incitação ao crime, devem ser avaliadas quando da solução dos conflitos entre normas de direitos fundamentais. Vale anotar que os desdobramentos em torno do que se tem denominado "pós-verdade" demandam aprofundamento e implicam revisitar o tópico.

Ainda quanto ao "conteúdo" (âmbito de proteção) da liberdade de expressão, importa destacar alguns aspectos. Assim, calha relembrar que a liberdade de expressão, nas suas diversas manifestações, engloba tanto o direito (faculdade) de a pessoa se exprimir quanto o de não se expressar ou mesmo de não se informar. Em primeira linha, a liberdade de expressão assume a condição precípua de direito de defesa (direito negativo), operando como direito da pessoa de não ser impedida de exprimir e/ou divulgar suas ideias e opiniões, sem prejuízo, todavia, de uma correlata dimensão positiva, visto que a liberdade de expressão implica um direito de acesso aos meios de expressão, o que não significa necessariamente um direto de acesso livre aos meios de comunicação social (CANOTILHO; MOREIRA, 2007, p. 572-573), muito embora tal componente também tenha adquirido uma crescente relevância em vários momentos (no caso brasileiro, por exemplo, o acesso dos partidos políticos aos meios de comunicação para efeitos de divulgação de seus programas, candidatos, sem falar do

\footnotetext{
8 Consigna-se que para os autores "a liberdade de expressão não pressupõe sequer um dever de verdade perante os factos embora isso possa vir a ser relevante nos juízos de valoração em caso de conflito com outros direitos ou fins constitucionalmente protegidos."

9 Para ilustrar, v. o reconhecimento, pelo STF, de proteção para manifestações não verbais. No HC 83.996/RJ (rel. Min. Gilmar Mendes, julgado em 17/08/2004), tratava-se de habeas corpus impetrado por um réu em ação penal, o qual se utilizou de gestos obscenos após um espetáculo teatral, incorrendo no artigo 288 do Código Penal. O STF decidiu, por maioria, que manifestações não verbais, como gestos e exibições, podem ser abarcados pelo âmbito de proteção da liberdade de expressão, sobretudo quando considerado o contexto em que se insere a manifestação. Segundo o relator para o acórdão, min. Gilmar Mendes, "um exame objetivo da querela há de indicar que a discussão está integralmente inserida no contexto da liberdade de expressão, ainda que inadequada ou deseducada." Pela sua relação com a liberdade de expressão, vale também citar a ADI 1.969-4 (rel. Min. Marco Aurélio, julgada em 24.03.99), em que se declarou a inconstitucionalidade de decreto que havia proibido o uso de carros de som, aparelhos e objetos sonoros nas manifestações realizadas na Praça dos Três Poderes, registrando-se, contudo, que o STF entendeu ter havido violação da liberdade de reunião e de manifestação.
} 
problema atinente ao direito de resposta), especialmente no que diz respeito à dimensão objetiva da liberdade de expressão.

Com efeito, também em relação à liberdade de expressão importa enfatizar que ela apresenta uma dupla dimensão subjetiva e objetiva, ou seja, operando como direito subjetivo individual (e mesmo coletivo, a depender do caso), tanto de matriz negativa (implicando deveres de abstenção), como já frisado, e, a depender do caso, direitos subjetivos a prestações, por sua vez, fortemente vinculados à dimensão objetiva, que importa em deveres estatais de proteção, em parte satisfeitos mediante a edição de normas de cunho procedimental e criação e regulamentação de instituições (órgãos) que atuam na proteção e promoção dos direitos, como é o caso, por exemplo, da criação, no plano constitucional, do conselho de comunicação social (artigo 224, CF).

Tais deveres de proteção, todavia, também vinculam os órgãos judiciais, aos quais incumbe não apenas zelar pela devida consideração dos direitos e interesses postos em causa concretamente no âmbito das relações entre sujeitos privados, mas também controlar a constitucionalidade dos atos estatais que interferem na liberdade de expressão. Aliás, a própria existência de tipos penais, agora na linha de tutela dos direitos correlacionados, como honra e privacidade, não deixa de ser desdobramento dos deveres estatais de proteção, o que será objeto de atenção logo na sequência.

\subsection{Notas sobre possíveis limitações à liberdade de expressão, em especial a partir de colisões com outros direitos fundamentais}

Dada a sua relevância para a democracia e o pluralismo político, a liberdade de expressão - pelo menos de acordo com significativa doutrina no Brasil - assume uma espécie de posição preferencial (preferred position), quando da resolução de conflitos com outros princípios constitucionais e direitos fundamentais, ${ }^{10}$ muito embora se afirme que no Brasil a teoria da posição preferencial - em que pese consagrada pelo STF quando do julgamento da ADPF n. 130 - tem sido, em geral, aplicada de forma tímida (KOATZ, 2011, p. 402), não sendo, de outra parte, reconhecida majoritariamente na Alemanha, onde a liberdade de expressão não assume uma prévia posição preferencial na arquitetura dos direitos fundamentais.

De qualquer modo, ainda que se admita a doutrina da posição preferencial, não se trata de atribuir à liberdade de expressão (em qualquer uma de suas manifestações particulares) a condição de direito absolutamente imune a qualquer limite e restrição, nem de estabelecer uma espécie de hierarquia prévia entre as normas constitucionais. Assim, quando se fala de uma posição preferencial o é para a finalidade de reconhecer à liberdade de expressão uma posição de vantagem no caso de conflitos com outros bens fundamentais no que diz respeito à hierarquização das posições conflitantes no caso concreto, de tal sorte que também nessa esfera - da solução para eventual conflito entre a

$\overline{10}$ Cf., por todos, na doutrina brasileira, Barroso (2005, p. 105-106). 
liberdade de expressão e outros bens fundamentais individuais e coletivos -, não há como deixar de considerar as exigências da proporcionalidade e de outros critérios aplicáveis a tais situações, o que se percebe é praticado mesmo pelo STF em algumas situações.

Vale aventar algumas hipóteses envolvendo o problema dos limites e restrições à liberdade de expressão, a iniciar pela (im)possibilidade do estabelecimento de qualquer tipo de censura, proibição expressamente prevista no artigo $5^{\circ}$, IX, da CF, associada à livre expressão da atividade intelectual, artística, científica e de comunicação, proibição que representa uma forte reação do constituinte ao passado recente, nomeadamente aos excessos praticados durante o período da Ditadura Militar, proibiç̧ão reiterada no artigo $220, \mathbb{\$} 2^{\circ}, \mathrm{CF}$, de acordo com o qual "é vedada toda e qualquer censura de natureza política, ideológica e artística." De qualquer sorte, é preciso reconhecer que a despeito de a censura já ter sido objeto de vedação constitucional anterior, isso não impediu que a censura viesse a ser amplamente praticada, como também ocorreu na vigência da assim chamada Ditadura do Estado Novo (1937-1945) (FARIAS, 2004, p. 186-187). A proibição da censura é de tal sorte relevante para a liberdade de expressão que, de acordo com o noticiado por Machado (2002, p. 487), "a liberdade de imprensa é, historicamente, a liberdade perante a censura prévia."

A absoluta vedação da censura que se infere da CF não dispensa uma definição do que seja censura, até mesmo para que seja possível diferenciar as situações à luz do ordenamento jurídico-constitucional. Numa primeira aproximação, por se tratar de uma noção amplamente compartilhada e em relação à qual existe um alto grau de consenso, a censura que se pode ter, de plano e em qualquer caso como absolutamente vedada pela CF, consiste, de acordo com a lição de Machado (2002, p. 486-487), na restrição prévia à liberdade de expressão realizada pela autoridade administrativa e que resulta na proibição da veiculação de um determinado conteúdo.

O quanto outras intervenções prévias (por exemplo, as estabelecidas por conta da proteção de outros bens fundamentais no caso de uma colisão entre estes e a liberdade de expressão) se enquadram na noção de censura e em que medida podem ser (ou não) constitucionalmente legítimas tem sido objeto de acirrado debate, prevalescendo o entendimento de que para assegurar a proteção da liberdade de expressão a proibição de censura e de licença deve ser compreendida em sentido amplo, de modo a abarcar não apenas a típica censura administrativa, mas também outras hipóteses de proibição ou limitação da livre expressão e circulação de informações e de ideias (FARIAS, 2004, p. 188).

O problema de uma definição demasiadamente ampla de censura, como abarcando toda e qualquer restrição à liberdade de expressão, é que ela acabaria por transformar a liberdade de expressão em direito absoluto, o que não se revela como sustentável pelo prisma da equivalência substancial e formal entre a liberdade de expressão e outros bens fundamentais, pelo menos a dignidade da pessoa humana e os direitos de personalidade. Por outro lado, tomando-se também a liberdade de expressão como abarcando as diversas manifestações que lhe são próprias, a liberdade de manifestação do pensamento, a liberdade de comunicação e de informação (relacionadas à liberdade de imprensa), a liberdade de expressão artística, apenas para citar as mais importantes, verifica-se que 
uma distinção entre censura e outras modalidades de restrição (que poderão, a depender do caso, ser constitucionalmente justificadas) é necessária até mesmo para preservar as peculiaridades de cada modalidade da liberdade de expressão.

De qualquer modo, na esteira do que lembra Sarmento (2013, p. 257), uma orientação geral importante a ser observada é a de que apenas em hipóteses absolutamente excepcionais são admissíveis restrições prévias ao exercício da liberdade de expressão, quando em causa a proteção de direitos ou outros bens jurídicos contrapostos, visto que a regra geral que se infere da CF é a de que os eventuais abusos e lesões a direitos devem ser sancionados e compensados posteriormente.

Por ora, considerado o contexto e por se tratar de situação corriqueira e prevista na CF, convém destacar que a classificação indicativa de espetáculos e diversões públicas pela autoridade pública não se confunde com a censura. Com efeito, basta a leitura do Texto Constitucional para que se perceba que este - pelo menos de acordo com uma interpretação literal - não abre margem para a proibição de um espetáculo, ainda que com o objetivo de proteção de crianças e adolescentes, visto que, a teor do artigo 220, $\mathbb{S} 3^{\circ}, \mathrm{I}, \mathrm{CF}$, apenas é conferida competência às autoridades responsáveis para que indiquem a faixa etária adequada para cada espetáculo, sugerindo locais e horários para sua apresentação.

Quanto a tal ponto, é de se sublinhar que, depois de longa disputa doutrinária e jurisprudencial, o STF no âmbito da ADI n. 2.404/2001, relatada pelo Ministro Dias Toffoli, no bojo da qual se buscava a declaração de inconstitucionalidade do artigo 254, do Estatuto da Criança e do Adolescente, que estabelece uma punição para a transmissão de espetáculo em horário diverso do autorizado, afirmou o caráter meramente indicativo das faixas etárias.

Particularmente relevante e polêmica é a hipótese de limitações não expressamente autorizadas pela constituição (seja a CF, seja a LF), em decorrência de conflitos entre a liberdade de expressão e a proteção de outros direitos e bens jurídicos fundamentais. Que também a liberdade de expressão, incluindo a liberdade de informação e de imprensa (comunicação social), não é absoluta e encontra limites no exercício de outros direitos fundamentais e na salvaguarda, mesmo na dimensão objetiva (por via dos deveres de proteção estatal) de outros bens jurídico-constitucionais, praticamente não é contestado no plano do direito constitucional contemporâneo e mesmo no âmbito do direito internacional dos direitos humanos.

Contudo, a controvérsia a respeito de quais são tais limites e de como e em que medida se pode intervir na liberdade de expressão segue intensa e representa um dos maiores desafios, especialmente para o legislador, mas também para os órgãos do Poder Judiciário, a quem compete, no caso concreto, e mesmo na esfera do controle abstrato de constitucionalidade e da legalidade, decidir a respeito. Embora expressamente vedada a censura de cunho ideológico, político e artístico - o que em hipótese alguma aqui se coloca em causa - a própria definição do que é censura para efeitos da vedação constitucional já levanta problemas que não são fáceis de equacionar. Mesmo que se adote uma noção ampliada de censura, não há como deixar de admitir que a censura, por mais que consti- 
tua uma forte (e proibida) intervenção na liberdade de expressão, não equivale, em termos gerais, à noção de limites e restrições. Controle do abuso da liberdade de expressão e censura são, portanto, noções que devem ser cuidadosamente diferenciadas.

De acordo com a precisa e oportuna síntese de Sarmento (2013, p. 257), muito embora a posição adotada pelo Ministro Carlos Ayres de Britto no julgamento da ADPF n. 130, quando sustentou que nenhum limite legal poderia ser instituído em relação à liberdade de expressão, pois as limitações existentes seriam apenas aquelas já contempladas no Texto Constitucional, cabendo tão somente ao Poder Judiciário fazer as ponderações pertinentes em caso de tensões com outros direitos, o Ministro Gilmar Ferreira Mendes, no voto condutor que proferiu no Rec. Ext. n. 511.961/SP, observou que as restrições à liberdade de expressão em sede legal são admissíveis, desde que visem a promover outros valores e interesses constitucionais também relevantes e respeitem o princípio da proporcionalidade.

Com efeito, ainda que excepcionais, restrições legislativas não expressamente autorizadas, mas que podem ser reconduzidas à CF, pelo fato de terem por fundamento a proteção de outros bens constitucionais relevantes, não podem, pelo menos não de plano, ser afastadas sob o argumento de que são sempre constitucionalmente ilegítimas. $O$ mesmo se verifica - e a prática nacional, estrangeira e internacional o tem demonstrado - no caso de restrições impostas por decisões judiciais, que, normalmente na solução de conflitos em concreto, buscam promover a concordância prática (harmonização) entre os direitos e princípios conflitantes, aplicando-se sempre a noção dos limites aos limites dos direitos fundamentais e os critérios disso decorrentes, tópico que escapa ao âmbito deste artigo.

Um exemplo de particular relevância no contexto da liberdade de expressão é o da prática do assim chamado discurso do ódio ou de incitação ao ódio (hate speech). ${ }^{11}$ Sem que aqui se possa adentrar os detalhes da problemática, nem rastrear as diversas formas de enfrentamento doutrinário e jurisprudencial do tema no direito comparado e internacional, corresponde ao entendimento dominante, no Brasil e em geral no direito comparado, que a liberdade de expressão encontra limites na dignidade da pessoa humana de todas as pessoas e grupos afetados quando utilizada para veicular mensagens de teor discriminatório e destinadas a incitar o ódio e, até mesmo, a violência. No âmbito do STF, o julgamento mais relevante e que gerou acirrada discussão no próprio tribunal foi o famoso caso Ellwanger, no qual se avaliou a possibilidade de, mesmo em face da liberdade de expressão, condenar editor de obras de teor antissemita pela prática do crime de racismo. ${ }^{12}$

\footnotetext{
11 Sobre o tema, v., dentre outros, Sarmento (2006, p. 207-262), bem como, no âmbito da produção monográfica especializada, Pflug (2009).

12 Cf. HC n. 82.424/RS, rel. Min. Maurício Corrêa, julgado em 17/09/2003, habeas corpus impetrado por réu em ação penal na qual estava sendo acusado do crime de racismo em virtude de ter publicado livros contendo manifestações de incitação de ódio contra os judeus, além de buscar desacreditar a ocorrência do genocídio praticado contra povo judeu (Holocausto) durante a Segunda Guerra Mundial.
} 
Aliás, o STF nesse leading case, verdadeiro paradigma quanto aos crimes de discriminação, ao considerar o antissemitismo crime de racismo e, portanto, imprescritível, rejeitou expressa tese defensiva que postulava interpretação restritiva, pela qual os judeus não configurariam raça, o que livraria o réu, ao menos, da imprescritibilidade. Pois, em uma interpretação extensiva, o STF debruçou-se sobre o termo racismo para delimitar sua abrangência; buscou compatibilizar os conceitos etimológicos, etnológicos, sociológicos, antropológicos ou biológicos, de modo a construir a definição jurídico-constitucional do termo: "Interpretação teleológica e sistêmica da Constituição Federal, conjugando fatores e circunstâncias históricas, políticas e sociais que regeram sua formação e aplicação, a fim de obter-se o real sentido e alcance da norma" - de ressaltar que se tratava de matéria penal, versando a interpretação sobre norma incriminadora (art. 20 da Lei n. 7.716/89, na redação dada pela Lei n. 8.081/90). ${ }^{13}$

Em julgado mais recente - embora também e mesmo essencialmente vinculado ao âmbito de proteção das liberdades de reunião e manifestação - o STF, no caso conhecido como a "Marcha da Maconha", ${ }^{14}$ ao apreciar a configuração de ilícito penal em virtude de a liberdade de expressão (coletiva, mediante reunião e manifestação) ter sido utilizada para buscar, mediante sensibilização da opinião pública, a descriminalização do uso de drogas leves para consumo próprio, afastou a figura típica da apologia de crime, por considerar tal manifestação como coberta pelas liberdades de expressão, reunião e manifestação, não se podendo, como decorre da fundamentação da decisão, confundir manifestação pública em prol da descriminalização de um determinado comportamento com a incitação à prática de tal ato, que, por sua vez, poderia, sim, configurar uma hipótese de discurso do ódio ou incitação ao crime não coberta pela liberdade de expressão.

A apologia de crime, numa imagem sugestiva de Vives Antón (2011, p. 814-832), parece ser um "fantasma que percorre o direito penal da democracia." ${ }^{15}$ Em suma, ao comentar a positivação do

\footnotetext{
13 Em lógica similar, tendo em vista o interesse para a análise da tipicidade como categoria geral do delito, cita-se: APELAÇÃO CRIMINAL. TRIBUNAL DO JÚRI. CRIME DOLOSO CONTRA A VIDA. TENTATIVAS DE HOMICÍDIO QUALIFICADO. LESÕES CORPORAIS. DANO AO PATRIMÔNIO PÚBLICO. MOTIM EM UNIDADE DA FASE. TIPICIDADE. DISTINÇÃO ENTRE INTERPRETAÇÃO EXTENSIVA E ANALOGIA. DECISÃO MANIFESTAMENTE CONTRÁRIA À PROVA DOS AUTOS. INOCORRÊNCIA. CONFIGURADA, ENTRETANTO, SENTENÇA DO JUIZ-PRESIDENTE CONTRÁRIA À DECISÃO DOS JURADOS. CONDENAÇÃO PELO CRIME DE MOTIM. DOSIMETRIA DA PENA READEQUADA. 1. [...] 2. A rebelião de internos cumprindo medida socioeducativa de internação, espécie do gênero privação de liberdade, autoriza a condenação pelo delito de motim, previsto no artigo 354 do Código Penal. Precedentes do Superior Tribunal de Justiça. A legalidade e seu precipitado técnico de tipicidade, no Estado democrático de direito, significa que o legislador cria, com o teor literal de um preceito, um marco de regulação que é preenchido e concretizado pelo juiz. Neste marco delimitado pelo sentido literal possível da linguagem, o juiz efetua a interpretação, considerando o significado literal mais próximo, a concepção do legislador histórico e o contexto sistemático-legal e segundo o fim da lei (interpretação teleológica), sendo que a interpretação pode ser tanto restritiva como extensiva. Ao revés, a aplicação do direito à margem do marco de regulação legal (lacuna), que não está coberta pelo sentido literal possível de um preceito penal, configura analogia incriminadora e, portanto, inadmissível. Trata-se, no caso dos autos, de interpretação sistêmica e teleológica do art. 354 do Código Penal, que conserva a redação original (1940), delimitada pelo sentido literal possível da linguagem textual e que se coaduna com o programa normativo, tendo em vista os fins cognoscíveis e as ideias fundamentais da regulação no que tange ao atual quadro constitucional e legal. Em suma, preso é o sujeito privado de liberdade, ainda que em face de internação prevista na Lei 8.069/90, e prisão é o estabelecimento em que cumpre a medida socioeducativa de internação. Decisão do Juiz-presidente que, no ponto, desgarrou do veredicto emanado do Corpo de Jurados. Réus condenados pelo delito de motim [...] (TJRS, Apelação Criminal n. 70070139449, Primeira Câmara Criminal, rel. Des. Jayme Weingartner Neto, j. 19/10/2016).

14 Cf. o julgamento da ADPF 187, rel. Min. Celso Mello, julgada em 15/06/2011.

15 Cf. Vives Antón (2011, p. 814-832), sobre "apologia do delito, princípio da ofensividade e liberdade de expressão."
} 
delito de apologia de crime no Código Penal Espanhol de 1995 (art. 18, 1, \1), nota que o tipo exige uma provocação que, por sua natureza e circunstâncias, constitui uma incitação direta a cometer um delito. Tal técnica redacional afasta críticas no sentido de que se estaria punindo a exposição de ideias, embora reste a dúvida acerca da necessidade de um delito autônomo nessa hipótese, pois a apologia somente seria punida como espécie de participação em delito específico. Entretanto, no mesmo Código, o art. 607.2 parece contradizer o preceito anterior, ao criminalizar a difusão de ideias ou doutrinas que neguem ou justifiquem (determinados) delitos, ou pretendam a reabilitação de regimes ou instituições que amparem práticas geradoras daqueles - isto é, castiga-se, aqui, a difusão de ideias por si mesmas.

Fica, no segundo caso, o problema da ofensividade, ou seja, qual bem jurídico seria protegido com a criminalização de apologia, pois, ao castigar a mera expressão de opiniões, não se produziria, para expressiva parcela da doutrina espanhola, um autêntico dano ou perigo para a sociedade. Vives Antón (2011), todavia, não considera tal prática inócua (figure-se a apologia de genocídio ou de terrorismo, a considerar que "a sociedade humana é um mecanismo que transforma ideias em realidades materiais"), mas pondera que algumas liberdades não podem ser combatidas se restringindo a liberdade, que há de se defender por si, sem ajuda da coação estatal (convoca-se a imagem do livre mercado de ideias). E nem mesmo o risco de que terceiros adquiram falsas crenças pelo exercício da liberdade de expressão alheia justificaria punir a mera apologia de ideias - um regime político que somente reconheça o direito a expressar a verdade seria uma negação em si da liberdade de expressão, também pela dificuldade epistemológica que cerca a verdade e os meios de alcançá-la. E se um terceiro cometer um delito, inspirado em uma ideia geral de outrem, age em virtude de um processo de deliberação racional e livre, pelo que pode e deve ser punido como ser autônomo e responsável pelos seus atos.

Vives Antón (2011) propõe uma concepção procedimental do bem jurídico-penal, que não o vê como objeto (sequer ideal), mas como justificação, "um momento do processo de justificação racional da limitação da liberdade" e, nesse ponto, se não se pode justificar racionalmente a ingerência na liberdade de expressão representada pela tipificação da apologia, isso quer dizer que não pode haver bem jurídico que justifique (tal ingerência) e que a conduta apologética não é lesiva, "por mais que possa assim nos parecer." ${ }^{16}$

De qualquer sorte, ainda que se possa - como compreende a produção bibliográfica que se produziu sobre o julgado da "Marcha da Maconha" - controverter a respeito dos acertos e dos equívocos da decisão no caso concreto, ${ }^{17}$ o fato é que o julgado do STF aponta - e quanto a isso

\footnotetext{
16 O contexto de justificação é um momento essencial do "contexto de sentido da norma penal" na concepção de Vives Antón. E a ideia de bem jurídico, sim, representa um limite ao legislador; não como um conceito, antes ao remeter aos "diversos preceitos constitucionais e suas tradições interpretativas."

17 Para uma síntese do julgamento e mesmo com notas críticas sobre a dispersiva fundamentação e a dificuldade de se considerar o julgado como autêntico precedente apto a dar conta do problema do discurso do ódio e situações similares, v. Koatz (2011, p. 434 e ss.).
} 
de modo correto - no sentido da ilegitimidade constitucional do discurso do ódio e da incitação à violência, preconceito e discriminação, considerando que a liberdade de expressão não contempla "manifestações de conteúdo imoral que implicam ilicitude penal"18 desde que, é claro, devidamente configurados.

Nessa senda, como bem pontua Branco (2001, p. 308), em passagem que se tomou a liberdade de transcrever,

contra o discurso de ódio - e também contra a ideia de que a pornografia possa estar incluída no âmbito normativo da liberdade de expressão -, há de se considerar, ainda mais, o efeito inibidor dessas práticas à plena participação dos grupos discriminados em diversas atividades da sociedade civil. A contumaz desqualificação que o discurso de ódio provoca tende a reduzir a autoridade dessas vítimas nas discussões de que participam, ferindo a finalidade democrática que inspira a liberdade de expressão.

Aliás, o problema do assim chamado discurso do ódio acabou sendo potencializado no ambiente digital, pela internet, com particular destaque para as redes sociais, gerando uma infinidade de discussões doutrinárias e jurisprudenciais, mas também levando, gradualmente, a uma sensibilização pelo legislador, como foi o caso da Alemanha, mediante a edição de uma legislação sancionando o discurso do ódio na internet. ${ }^{19}$

Se quanto ao discurso do ódio e a manifestações de cunho claramente antidiscriminatório se verifica - ressalvada, evidentemente, controvérsia sobre quando configuradas tais manifestações - substancial consenso no sentido de admitir restrições mais fortes na liberdade de expressão, outras hipóteses em que a liberdade de expressão entra em conflito com direitos fundamentais de terceiros e outros bens constitucionais individuais e coletivos são de mais difícil equacionamento.

Entre as situações mais corriqueiras e que já geraram farta jurisprudência no Brasil e no exterior, incluindo a atuação dos Tribunais Internacionais, está a proibição de manifestações (publicações, filmes, etc.) de cunho pornográfico e de manifestações culturais e artísticas consideradas ofensivas à moral, aos bons costumes e mesmo à dignidade da pessoa humana e aos direitos de personalidade de terceiros. Ao passo que cláusulas gerais como a moral e os bons costumes se revelam como extremamente perigosas para justificar restrições à liberdade de expressão ${ }^{20}$ (salvo eventualmente no campo das indicações das faixas etárias, a título de recomendação aos pais de crianças e adolescentes), em geral não se coloca em questão o fato de que a dignidade da pessoa humana, como princípio e direito fundamental, bem como a afetação desproporcional de direitos fundamentais de

\footnotetext{
18 Cf. referência extraída da ementa (item 13) do Acórdão do HC n. 82.424 (Caso Ellwanger).

19 O Parlamento da Alemanha aprovou no dia 30 de junho de 2017 lei que impõe a retirada de manifestações que caracterizam o discurso do ódio, de conteúdo xenófobo, racista, entre outras, do Facebook, prevendo sancionamento pecuniário que pode alcançar milhões de euros. A medida tem sido objeto de acirrada polêmica, não sendo o caso aqui de desenvolver o ponto. 20 Para um descarte do "atalho" da moral pública e dos bons costumes como limite para restringir liberdades fundamentais, no contexto da liberdade religiosa, veja-se Weingartner Neto (2007, p. 212-213).
} 
terceiros, especialmente em se tratando de direitos de personalidade, há de ser sempre considerada na esfera de uma ponderação à luz das circunstâncias do caso.

Avaliando-se, nesse contexto, a jurisprudência do STF, verifica-se que este, em geral, tem sido adequadamente deferente à liberdade de expressão, admitindo intervenções em situações excepcionais e normalmente constitucionalmente justificadas (o que não significa que não se possa questionar o acerto de alguns julgados ou avaliar criticamente os fundamentos das decisões).

Apenas para referir alguns exemplos, têm sido aceitas manifestações eventualmente impopulares e que possam mesmo ofender o senso comum na esfera da opinião pública, como ocorreu no caso já citado da "Marcha da maconha", bem como admitidas manifestações de cunho humorístico e crítico (charges, publicidade, literatura em geral). ${ }^{21}$ Até mesmo manifestações que em outro contexto (v.g., na via pública, em meio a crianças) poderiam ser tidas como ilícitas, por seu tom obsceno e/ou pornográfico, devem ser abarcadas pela liberdade de expressão, ainda que, na perspectiva dominante, pudessem ser no mínimo rotuladas como impróprias ou de "mau gosto". ${ }^{22}$

Situações particularmente relevantes e que envolvem corriqueiro embate entre a liberdade de expressão e outros direitos fundamentais, diz com os direitos à honra, à imagem, à intimidade e à vida privada - tópicos penais relativos aos crimes contra a honra serão desenvolvidos adiante. No que se refere aos direitos à honra e à imagem (incluindo a reputação), direitos personalíssimos cuja violação inclusive configura ilícito penal, distinguem-se, de plano, os casos que envolvem personalidades públicas, como é o caso de artistas famosos, políticos e outras pessoas notórias, cuja atividade e modo de se portar na esfera pública (v. os casos de pessoas que se expõe - inclusive quanto a aspectos de sua vida íntima - reiterada e voluntariamente nos meios de comunicação) das demais pessoas, de modo a assegurar também níveis diferenciados de proteção da personalidade, a depender do caso concreto de quem é atingido pelo exercício da liberdade de expressão e de como é atingido.

Por tal razão, onde houver maior interesse (legítimo) da opinião pública sobre informações a respeito das ações e vida privada de alguém, ou mesmo, como já frisado, o próprio titular dos direitos de personalidade tenha já voluntariamente exposto sua vida privada, justifica-se uma menor

\footnotetext{
$\overline{{ }_{21}}$ Em caráter ilustrativo, cabe referir o julgamento da ADI n. 4.451 (rel. Min. Ayres Britto, julgada em 02/09/2010), em que a Corte, por maioria, declarou a inconstitucionalidade de dispositivos da Lei n. 9.504/97, que restringiam o humor nos veículos de telecomunicação, quando se tratasse de programas envolvendo candidatos a cargos eletivos dentro do período eleitoral.

22 Nesse sentido, v., por exemplo, o caso do HC n. 83.996-7/RJ (rel. Min. Gilmar Mendes, julgado em 17/08/2004), no qual, por maioria, foi determinado o trancamento de ação penal por atentado ao pudor instaurada contra diretor teatral que, em protesto contra vaias proferidas pela plateia, expôs suas nádegas ao público, além de simular masturbação. Note-se que o Tribunal considerou o ato atípico, entendendo estar a discussão (entre o público e o artista) inteiramente abrangida pelo âmbito de proteção da liberdade de expressão, sendo que a sociedade moderna dispõe de mecanismos próprios e adequados para tal situação, como a própria crítica, dispensável o enquadramento penal. $\bigcirc$ trancamento da ação penal decorreu de empate, prevalecendo regimentalmente o voto de dois ministros que não viram tipicidade em face do conceito normativo de pudor público, que não teria sido ofendido pela liberdade de expressão do paciente. $\bigcirc$ Min. Gilmar referiu, no final do voto, que remanesceria eventual injúria, mas dirigida contra um grupo e não a pessoas individualizadas e, de toda sorte, não houve queixa-crime.
} 
proteção - mas não supressão! - da honra, da imagem e da vida íntima e privada e um maior espaço para a liberdade de informação e expressão. ${ }^{23}$

À vista do exposto, o que se pode afirmar, em caráter de síntese e retomando a perspectiva adotada já na parte inicial desta subseção, é que boa parte da doutrina e da jurisprudência, notadamente o STF, embora adote a tese da posição preferencial da liberdade de expressão, admite não se tratar de direito absolutamente infenso a limites e restrições, desde que eventual restrição tenha caráter excepcional, seja promovida por lei e/ou decisão judicial (visto que vedada toda e qualquer censura administrativa) e tenha por fundamento a salvaguarda da dignidade da pessoa humana (que aqui opera simultaneamente como limite e limite aos limites de direitos fundamentais) e de direitos e bens jurídico-constitucionais individuais e coletivos fundamentais, observados os critérios da proporcionalidade e da preservação do núcleo essencial dos direitos em conflito.

Que, em qualquer caso, existindo dúvida a respeito da legitimidade constitucional da restrição, é de se privilegiar a liberdade de expressão, segue sendo um parâmetro que não deve cair jamais em esquecimento, desde que se o maneje em harmonia com outros valores constitucionais cruciais. Isso se revela particularmente importante no domínio do direito penal e na compreensão do alcance dos tipos penais em face da maior ou menor amplitude do conteúdo das liberdades comunicativas. É precisamente isso que será objeto de nossa atenção, mediante uma análise focada em alguns exemplos.

\section{Liberdade de expressão e sua repercussão na esfera penal: o caso dos crimes contra a honra}

Dando encaminhamento ao que foi anunciado na parte introdutória, é o caso de se indagar, na perspectiva jurídico-penal, acerca da compreensão mais ou menos elástica dos tipos penais que dizem respeito aos crimes contra a honra. Para tanto, a pergunta que se objetiva responder é a que segue: qual o limite para manifestações potencialmente ofensivas da honra, de modo que mereçam a incidência das sanções previstas pela legislação penal?

Adianta-se entendimento no sentido de que a crítica objetiva é fato atípico, portanto, um indiferente penal. Para melhor compreensão do ponto, invoca-se aqui sentença do Tribunal Constitucional Federal da Alemanha, muito citada (Soldaten sind Mörder), ou seja, o caso dos "soldados são assassinos". No caso, cuidava-se de integrantes de movimento pacifista que haviam sido condenados criminalmente pela jurisdição ordinária, por terem afirmado que soldados seriam assassinos (ou assassinos em potencial). O recurso constitucional alegava atentado contra a "liberdade de expressão". O primeiro Senado da Corte Constitucional gizou que a "aplicação da norma penal relativa aos crimes contra a honra envolve uma inevitável tensão entre a proteção da honra e a liberdade

${ }_{23}$ Cf., por todos, Barroso (2005, p. 115), elencando, ainda, outros critérios de aferição dos níveis de proteção e realização dos direitos colidentes. 
de expressão, que não se deixa resolver de forma geral e abstrata, sem referência ao caso concreto." Enfatizou o "significado constituinte e constitutivo da liberdade de expressão para a ordem liberal e democrática", pelo que o interesse legítimo abarcava manifestação no contexto de uma "controvérsia pública sobre um tema de relevância política ou social." ${ }^{24}$

Segundo a Corte, na crítica genérica a um grupo ou coletividade é "difícil traçar uma linha de separação entre a proteção da honra e a crítica a fenômenos sociais ou às instituições do Estado"; e quanto mais expressiva essa coletividade, menos significativa a lesão no plano pessoal (essa crítica ao coletivo estaria muito próxima de uma crítica de fenômeno social, sem aptidão para lesar a honra pessoal). Enfim, ainda segundo a Corte, as afirmações pretendiam "suscitar uma discussão objetiva sobre um tema de relevo para a formação da opinião pública" (a questão moral da guerra e do serviço militar obrigatório), pelo que subsistiria a presunção em favor da liberdade de expressão, salvo demonstração em contrário, que caberia aos tribunais ordinários, de que o objetivo central da manifestação era ofender e não discutir um relevante tema público.

$\mathrm{Na}$ mesma linha de entendimento, situa-se decisão da Corte Constitucional Espanhola proferida em 1987, afirmando a prevalência da liberdade de expressão:

A liberdade de informação é, em termos constitucionais, um meio de formação da opinião pública em assuntos de interesse geral, cujo valor de liberdade preferencial (libertad preferente) sobre outros direitos fundamentais e o direito à honra, salientado pela STC 104/1986, de 17 de julho, vem determinado por sua condição de garantia da opinião pública, que é uma instituição constitucional do Estado democrático que os poderes públicos têm especial obrigação de proteger. ${ }^{25}$

Vale complementar a citação, pois as distinções feitas pelo Tribunal ilustram a fronteira móvel da preferred position:

Este valor preferencial alcança seu nível máximo quando a liberdade é exercida pelos profissionais da informação através do veículo institucionalizado de formação da opinião pública, que é a imprensa, entendida na sua mais ampla acepção. Isto, entretanto, não significa que a mesma liberdade não deva ser reconhecida em iguais termos aos que não ostentam igual qualidade profissional, pois os direi-

\footnotetext{
${ }_{24}$ A Corte enumerou um elenco de tópicos que forneciam critérios para a ponderação concreta: a) a liberdade de expressão não se pode sobrepor à ideia de dignidade da pessoa humana; b) no caso de "injúria formal", a proteção da honra "assume relevância em face da liberdade de expressão", embora defina restritivamente crítica injuriosa/caluniosa (quando a declaração deixa de enfocar a controvérsia objetiva e passa a ter como objetivo central a difamação da pessoa), pelo que somente em casos excepcionais poderá se configurar tal limite à liberdade de expressão; c) se a manifestação não se enquadra como "ofensa à dignidade humana ou como calúnia ou difamação", então é de ponderar a intensidade de intervenção nos bens afetados - irrelevante, assim, a crítica mostrar-se justificada ou o juízo de valor "correto". Se a manifestação ultrapassa o âmbito da discussão privada e contribui para a formação da opinião pública, opera-se uma "presunção em favor da liberdade de expressão". Segue-se a resenha de Andrade (1996, p. 46-49). À página 47, o autor caracteriza a relação entre liberdade de imprensa e valores conflituantes como dinâmica, sem "fronteiras pré-determinadas e fixas. É o próprio relevo constitucional da liberdade de imprensa que condiciona o alcance com que os valores conflituantes a podem balizar. Por outro lado, as normas de direito (penal) ordinário que de algum modo estabelecem limites à liberdade de imprensa estarão sempre 'iluminadas com a luz da Constituição', devendo, por isso, ser sempre interpretadas a partir do programa de tutela da liberdade de imprensa consignado na Constituição."

25 STC 165/1987, de 27 de outubro - cf. Salvador Coderch (1990, p. 74 e ss.): uma associação comunitária de Barcelona publicara, sem assinatura, uma nota, no contexto de uma disputa em torno de um despejo, que qualificava o beneficiário de "corvo", membro de uma "corja de indivíduos sem escrúpulos". O Presidente da associação, José Pitarque, foi condenado por injúria grave a um ano de desterro a $100 \mathrm{~km}$ da localidade.
} 
tos de personalidade pertencem a todos sem estar subordinados às características pessoais de quem os exerce e sim ao conteúdo do próprio exercício. Entretanto, significa que o valor preferencial da liberdade declina quando não se realiza pelos leitos normais de formação da opinião pública, antes por meios tão anormais e irregulares como é a difusão de panfletos clandestinos, em cujo caso é de entender-se, no mínimo, que a relação de preferência que tem a liberdade de informação em relação à honra inverte-se a favor desta última, debilitando a eficácia justificadora daquela frente às lesões infligidas a esta. (SALVADOR CODERCH, 1990, p. 74 e ss.).

É preciso, pois, "recuar a tutela jurídico-penal da honra, introduzindo-lhe as limitações indispensáveis à conservação do núcleo essencial do direito de informação, máxime no que toca ao livre exercício da função pública da imprensa." (DIAS, 1983, p. 106). Não carece de demonstração o quanto o exercício do direito de crítica, que se insere no âmago da liberdade de imprensa, pode contender com os bens jurídicos em apreço, especialmente a honra. Têm-se em mente, para ilustrar, as apreciações sobre matérias científicas e acadêmicas, artísticas e desportivas, profissionais, etc., que pululam nas páginas dos periódicos hoje em dia, em tensão e mesmo conflito direto com outros direitos fundamentais.

O que importa sublinhar é que se parte aqui da premissa de uma crítica objetiva, parâmetro para que a manifestação sequer adentre no limiar da tipicidade penal, não sendo de natureza subjetiva, porquanto não se dirige ao sujeito, à pessoa do político, do artista, do atleta, do professor. Vale dizer que tal juízo será atípico

enquanto a valoração e censura críticas se atêm exclusivamente às obras, realizações ou prestações em si, não se dirigindo directamente à pessoa dos seus autores ou criadores [...] já porque não atingem a honra pessoal do cientista, artista ou desportista, etc., já porque não a atingem com a dignidade penal e a carência de tutela penal que definem e balizam a pertinente área de tutela típica. (ANDRADE, 1996, p. 233).

A partir dessas premissas, pode-se fixar três pontos. Em primeiro lugar, considerando o regime de atipicidade, não importa a pertinência, o conteúdo, o acerto da crítica, ou mesmo se resultado de apreciação criteriosa de expert ou de bravata ignorante de curioso, desde que mantida no limite da objetividade, convém lembrar. Segundo, não há limite para a virulência da expressão utilizada. ${ }^{26}$ Terceiro, esse regime dogmático vale especialmente para a crítica dirigida contra o atuar das instâncias públicas: o exercício administrativo em geral, a atividade parlamentar e do órgão legislativo, a direção política do governo, o mérito e a conveniência de manifestações do Ministério Público e dos despachos e sentenças dos juízes e tribunais.

Em síntese, a jurisprudência do Tribunal Constitucional Federal Alemão posicionou-se com clareza nas décadas de 1980 e 1990 a favor da "maximização do campo da intervenção lícita da

\footnotetext{
${ }^{26}$ Garimpadas da jurisprudência alemã, "pode apodar-se de pornográfica uma revista de análise política, caracterizar-se uma obra de arte como monte de estrume, uma prática médica como bruxaria ou curandeirismo, uma atuação política como própria de velhos e novos fascistas, uma acusação penal como inquisitória, persecutória, kafkiana, uma sentença como um disparate ou um chorrilho de venerandas asneiras." (ANDRADE, 1996, p. 237).
} 
atividade jornalística e, reversamente, de um estreitamento da tutela penal da honra." Em caráter ilustrativo, refere-se, aqui, o caso Bayer, julgado em 09 de outubro de 1990, de onde se pode extrair os argumentos centrais dessa construção jurisprudencial. Segundo o Tribunal Constitucional (apud ANDRADE, 1996, p. 270-273),

$\mathrm{O}$ art. $5^{\circ}$, I, 1, da Lei Fundamental assegura a todos o direito de emitir e divulgar livremente a sua opinião. [...] Elas [as opiniões] gozam da protecção do direito fundamental independentemente de a expressão ser valiosa ou sem interesse, certa ou errada, fundada ou sem fundamento, emocional ou racional. Também as expressões mordazes e exageradas caem fundamentalmente na área de proteção [...] Pelo contrário, a divulgação de um facto já não configura em rigor qualquer expressão de uma opinião [...] [As imputações de fatos] são protegidas pelo direito fundamental da liberdade de expressão se e na medida em que constituam pressuposto da formação das opiniões que o art. $5^{\circ}$, II, 1 , garante [...] [e a proteção] só acaba quando elas já nada possam contribuir para a formação da opinião constitucionalmente pressuposta. [...] a informação errada não constitui nenhum bem digno de tutela. [...] De todo modo, as exigências do dever de (procura da) verdade não deverão ser colocadas tão alto que ponham em causa a função da liberdade de expressão.

Pela sua primordial importância em relação à disputa política, cabe ainda o esboço da doutrina da presunção de legitimidade a favor dos juízos de valor na esfera essencialmente pública, o que significa, a acompanhar o Tribunal Constitucional Alemão, alargar e reforçar os juízos de valor "ofensivos da honra formulados no contexto da luta política democrática, designadamente no ambiente das campanhas eleitorais." Nas palavras da Corte, no Zwangsdemokraten-Urteil (1991), "terão de suportar-se críticas que são expressas em fórmulas exageradas e polémicas [...] [para evitar] o perigo de uma paralisação ou estreitamento indesejável do processo de formação da opinião pública." Todavia, e por outro lado, há a barreira da crítica eminentemente injuriosa e degradante (schmähkritik), outra das pedras angulares da construção do Tribunal Constitucional. A moldura da crítica caluniosa, antes de firmar-se em nível constitucional, começou por ser invocada pelo BGH, com afloramentos inequívocos no Höllenfeuer-Urteil (1966), que a consignou de forma cristalina no caso dos "Velhos e novos fascistas" (1974): permite-se "a crítica contundente, impiedosa, mesmo 'chocante', desde que tenha ainda uma referência objectiva (sachbezogen). Mas já não cobre nenhuma Schmähkritik, isto é, uma crítica que passa a ser um (mero) ataque doloso à honra." O conceito foi desenvolvido pelo Tribunal Constitucional (apud ANDRADE, 1996, p. 288-293), por exemplo no caso dos "Democratas à força" (1990):

É de se considerar como Schmähung a expressão de uma opinião que, para além da crítica polémica e exagerada, consiste na degradação da pessoa [...] Uma expressão degradante só assume o carácter de Schmähung quando nela não avulta em primeiro plano a discussão objectiva das questões mas antes o enxovalho das pessoas. Para além da crítica polémica e extremada tem de se visar o rebaixamento da pessoa.

Em síntese, a exceção à imunidade da crítica objetiva é a manifestação caluniosa e manifestamente degradante e humilhante. 
Focando agora ao ambiente brasileiro, onde o problema também se afigura como sendo de alta relevância e controvérsia, calha indagar se "argumentação ofensiva ao Poder Executivo Municipal", em vez de "atingir diretamente o Chefe deste Poder", não seria natural e legítimo exercício do direito constitucional de expressão em relação aos assuntos da vida pública, solução aqui escolhida. Não há, pois, crime contra a honra, em um quadro de crítica objetiva, certo que aguda e até ferina, mas que guarda liame com o tema comunitário abordado. No âmbito da dogmática penal, importa frisar, a situação traduz-se pela figura da atipicidade, o que também se aplica, mesmo que veiculada mediante fortes opiniões, à crítica social que não subjetiva qualquer imputação.

Em suma, é perfeitamente legítimo que um cidadão se manifeste fortemente contra um ato administrativo ou corporativo (com relevância pública) e questione sua conveniência, seu mérito e mesmo sua legalidade. Cuida-se de algo que, nas sociedades democráticas, deve ser debatido pela comunidade e veiculado pelos jornais, na concretização de um livre mercado de ideias, não ingressando na esfera penal, sequer em seu limiar mínimo de tipicidade.

À vista do exposto e para melhor ilustrar a questão, colaciona-se caso julgado pela Terceira Câmara Criminal do Tribunal de Justiça do Rio Grande do Sul (RIO GRANDE DO SUL, 2013). Versava a celeuma em torno de tráfico de influências na Empresa Brasileira de Correios e Telégrafos, concretamente aparelhamento político-partidário na movimentação e distribuição de cargos de confiança no âmbito da empresa pública. Esse é o cerne da polêmica, na qual digladiavam a direção da empresa (de nomeação política e que alegava ofensa à honra de dirigentes - querelantes) e a representação sindical dos trabalhadores de carreira da empresa (que seriam os responsáveis pelas ofensas e, por isso, querelados).

O juízo a quo estruturou a decisão que rejeitou a queixa-crime em duas considerações: (i) a inicial descreve assertivas genéricas dirigidas à Direção Regional da Companhia de Correios e Telégrafos, sem mencionar o nome dos querelantes (e nem seria possível identificar, dentre os integrantes da diretoria do sindicato, quais são os responsáveis pela edição do comunicado ofensivo); e (ii) as críticas, justas ou injustas, estão cobertas pela liberdade de expressão (arts. $5^{\circ}$, IV, e 220, ambos da CF), a redundar em conduta atípica.

Tem-se que está substancialmente correta a decisão. Quanto ao item (i), indubitável que foi o sindicato o responsável pelo panfleto indigitado, é bastante razoável, ao menos para desencadear a persecução penal, inserir no polo passivo da ação penal a Diretoria Colegiada SINTECT/RS, que, aliás, expressamente assina o documento e, portanto, assume a priori a autoria. A exata contribuição de cada um, individualmente, é matéria a ser examinada e controvertida ao longo da instrução, garantidos o contraditório e a ampla defesa. Essa, aliás, a orientação do STF, em crimes multitudiná$\operatorname{rios}^{27}$ e societários, ou de autoria conjunta ou coletiva, que pode ser aplicada analogamente ao caso examinado, pois o suposto crime teria sido praticado por intermédio da pessoa jurídica. 
A questão, todavia, perde relevo em face do item (ii) que, segundo aqui pensado, reconhece a crítica objetiva em matéria de interesse público e, portanto, a prevalência da liberdade de expressão e informação e, no campo penal, o regime da atipicidade. Que o assunto era de interesse público, é pouco menos que óbvio. Os lindes da crítica objetiva, nesse contexto, são evidentes, propondo-se discussão sobre os critérios de nomeação para altos cargos de crucial e estratégica empresa pública, no cenário nacional em que campeia a crítica à partidocracia divorciada dos interesses comunitários mais prementes, a comprometer a eficiência do poder público e a distorcer a democracia representativa, com reflexos na própria legitimidade do sistema político (a "voz das ruas" do Brasil de junho de 2013, de modo confuso, desarticulado e talvez raivoso, deliba tais questões de fundo). ${ }^{28}$

Entretanto, no documento havia duas expressões fortes, formalmente capazes de caracterizar, em tese, crime contra a honra:

Trazemos esta denúncia para a categoria inteira ficar ciente do que está ocorrendo, indignar-se conosco e juntos nos mobilizarmos para pôr um basta nesta verdadeira corrupção dentro de nossa empresa, onde os interesses políticos e pessoais determinam o privilégio de meia dúzia em detrimento da sobrecarga da maioria. FORA DIREÇÂO CORRUPTA DA DR/RS! CHEGA DE PRIVILÉGIO PARA OS AMIGOS DO REI. (RIO GRANDE DO SUL, 2013).

As frases em itálico são grosseiras, ofensivas, lamentáveis, mas não chegam a caracterizar a crítica caluniosa, mero pretexto para ofensa pessoal desconectada do tema em debate. Tolerar, em sede penal (que a esfera cível permanece em aberto para eventual avaliação e recomposição de direitos personalíssimos arranhados), tal virulência, que depõe contra seus autores, é o preço a pagar pelo necessário alargamento do âmbito da liberdade de expressão na prossecução de interesses legítimos, como esclarecer a opinião pública ou denunciar, de boa-fé, desmandos administrativos ou desvios políticos. ${ }^{29}$

No contexto do panfleto, claramente a expressão corrupção/direção corrupta articula-se com o tema tráfico de influência/loteamento de cargos por critérios primordialmente partidários. Desimporta se tais fatos restaram demonstrados ou não, não cabendo ao Poder Judiciário, nessa lide, juízo de mérito sobre os eventos, e assumindo-se socialmente o risco de que não se possa demonstrar, para evitar o chilling effect, ou seja, a autocensura, o amordaçamento das instâncias críticas.

Observa-se, no caso, que o panfleto foi reproduzido por e-mail, mas a própria queixa-crime aduz que foi encaminhado "a todos os seus associados, delegados e demais trabalhadores da

coletiva, a denúncia pode narrar genericamente a participação de cada agente, cuja conduta específica é apurada no curso da ação penal. Precedentes. O Código Penal, ao tratar do concurso de pessoas, prevê as figuras de autor, co-autor e partícipe, podendo, assim, ser parte passiva legítima na ação quem, de qualquer modo, concorre para o crime (art. 29), ainda que não tenha praticado a conduta prevista no tipo penal. [...] Habeas corpus conhecido, mas indeferido (BRASIL. STF, HC 75.868-8 RJ, Segunda Turma, rel. Min. Maurício Corrêa, julgado em 10/02/1998).

${ }_{28}$ Cf. Castells (2013, p. 178-179). Para uma exploração sobre o aumento da intolerância e da violência no Brasil, problematizando o conceito de fundamentalismo e chamando direitos constitucionais de reunião e de expressão para, no quadro do pluralismo intercultural, maximizar a voz das ruas e evitar reações estatais desproporcionais por meio da repressão penal, veja-se Weingartner Neto (2017).

29 Especificamente sobre tal causa especial de justificação penal, originada na Alemanha e legalmente prevista em Portugal, confira-se em Weingartner Neto (2002, p. 205 e ss.). 
categoria" - em princípio, justamente, o âmbito dos primeiros e mais diretamente interessados; e o periódico $O$ Mensageiro é o veículo por excelência de comunicação do sindicato. Portanto, longe se está de panfletos clandestinos ou evidentemente orientados pela vontade de crítica caluniosa contra os querelantes, mais preocupados em espalhar exponencialmente o teor ofensivo.

Ademais, apenas em reforço, o assunto teve repercussão na imprensa estadual. Confira-se:

Justiça impede cargos de confiança nos Correios. A Justiça do Trabalho proibiu os Correios de contratarem novos servidores sem concurso e analisa pedido do Ministério Público para que pessoas já contratadas nessas condições sejam demitidas. Em julho de 2011, ano em que o PT assumiu o controle da empresa, o estatuto foi modificado para permitir o loteamento de cargos. A mudança no estatuto dos Correios permitiu ao presidente da empresa e a cada um dos oito vice-presidentes contratarem duas pessoas cada, sem concurso público, em um total de 18 cargos de confiança. O Ministério Público do Trabalho obteve decisão liminar, após ingressar com ação na Justiça por considerar que as vagas não poderiam ser criadas sem autorização do Congresso e que esses postos deveriam ser preenchidos por pessoas concursadas. (JUSTIÇA..., 2013, p. 8).

Trata-se apenas de reafirmar o interesse comunitário no tema em debate, inadequado tecer qualquer comentário contra ou a favor das teses veiculadas pelas partes em conflito - tal debate há de prosseguir na esfera pública, sem o estigma do direito penal.

\section{Considerações finais}

Chega-se ao fim desse percurso constitucional-penal em condições de responder à indagação inicial, posta como hipótese, demonstrada mediante recurso a casos práticos e na perspectiva do marco normativo constitucional, em especial aplicando as premissas teórico-jurisprudenciais atinentes ao regime da liberdade de expressão, no sentido de que a manifestação pautada pela crítica objetiva, afastada não se reveste de tipicidade penal, portanto, a configuração de eventual crime contra a honra.

Observa-se que reservar o tratamento da atipicidade ao largo espectro da crítica objetiva fomenta sobremaneira o espaço de liberdade da esfera pública, encorajando o debate inspirado pelo interesse público, o que parece de especial relevância em tempos que garantir a transparência dos negócios públicos e possibilitar a alternância política e a manifestação das minorias é vital para a sobrevivência da própria democracia, lançando-se uma ponte virtuosa entre a dogmática penal e a consagrada categoria constitucional dos direitos fundamentais.

Tal orientação se encontra, por outro lado, afinada, para além da celeuma em torno de uma posição preferencial da liberdade de expressão, na senda da diretriz (absorvida majoritariamente pela teoria dos direitos fundamentais e consagrada também na jurisprudência do STF, mormente em matéria de liberdades comunicativas) de que restrições a direitos fundamentais devem ser interpretadas restritivamente, otimizando a proteção de cada direito objeto de eventual intervenção restritiva. Vale dizer que expressões e até eventuais excessos, abrigados pela crítica objetiva, sequer alcançam o limiar 
mínimo de relevância penal, desencorajando a utilização da persecução penal para assombrar a cidadania e os críticos dos governos de plantão, com a ressalva já apontada da crítica caluniosa em si.

Apenas assim - sem abrir mão da necessária consistência dogmática (segurança jurídica, previsibilidade e aderência ao marco jurídico-constitucional) - estar-se-á levando a sério a harmonização (concordância prática) entre a liberdade de expressão e a proteção de direitos fundamentais colidentes.

\section{Referências}

ANDRADE, Manuel da Costa. Liberdade de imprensa e inviolabilidade pessoal: uma perspectiva criminal. Coimbra: Coimbra Editora, 1996.

BARROSO, Luis Roberto. Liberdade de Expressão versus direitos da personalidade. Colisão de direitos fundamentais e critérios de ponderação. In: Temas de Direito Constitucional, Tomo III. Rio de Janeiro: Renovar, 2005. p. 79-130.

BRANCO, Paulo Gustavo Gonet. Liberdades. In: MENDES, Gilmar Ferreira; BRANCO, Paulo Gustavo Gonet (Org.). Curso de Direito Constitucional. 6. ed. São Paulo: Saraiva, 2011. p. 296-361.

CANOTILHO, José Joaquim Gomes; MOREIRA, Vital. Constituição da República Portuguesa anotada. 4. ed. Coimbra: Ed. Coimbra, 2007. v. 1.

CASTELLS, Manuel. Redes de indignação e esperança: movimentos sociais na era da internet. Rio de Janeiro: Zahar, 2013.

DIAS, Jorge de Figueiredo. Direito da Informação e Tutela da Honra no Direito Penal da Imprensa Português. Revista de Legislação e Jurisprudência, ano 115, p. 100-107, 1983.

EPPING, Volker. Grundrechte. 3. ed. Berlin-Heidelberg-New York: Springer, 2007.

FARIAS, Edilsom. Liberdade de Expressão e Comunicação: teoria e proteção constitucional. São Paulo: Revista dos Tribunais, 2004.

FECHNER, Frank. Art. 5, Meinungsfreiheit, Pressefreiheit u.a. In: STERN, K.; BECKER, F. (Ed.). Grundrechte-Kommentar. Köln: Carl Heymanns Verlag, 2010. p. 505-656.

JUSTIÇA impede cargos de confiança nos Correios. Jornal Zero Hora, 23 out. 2013. Política, p. 8.

KOATZ, Rafael Lorenzo-Fernandez. As liberdades de expressão e de imprensa na jurisprudência do Supremo Tribunal Federal. In: SARMENTO, Daniel; SARLET, Ingo Wolfgang (Coord.). Os Direitos Fundamentais no Supremo Tribunal Federal: balanço e crítica. Rio de Janeiro: Lumen Juris, 2011. p. 391-448.

MACHADO, Jónatas Eduardo Mendes. Liberdade de Expressão: Dimensões Constitucionais da Esfera Pública no Sistema Social. Coimbra: Coimbra Editora, 2002.

MICHAEL, Lothar; MORLOK, Martin. Grundrechte. Baden-Baden: Nomos, 2008. 
MICHELMAN, Frank. Relações entre democracia e liberdade de expressão: discussão de alguns argumentos. In: SARLET, Ingo Wolfgang (Org.). Direitos Fundamentais, Informática e Comunicação. Porto Alegre: Livraria do Advogado, 2007.

PFLUG, Samantha Meyer. Liberdade de Expressão e Discurso do Ódio. São Paulo: Revista dos Tribunais, 2009.

RIO GRANDE DO SUL. Tribunal de Justiça do Rio Grande do Sul. Recurso em Sentido Estrito n. 70054843966. Terceira Câmara Criminal. Rel. Des. Jayme Weingartner Neto. Julgado em 28 nov. 2013.

SALVADOR CODERCH, Pablo. El Mercado de las ideas. Madrid: Centro de Estudios Constitucionales, 1990.

SARMENTO, Daniel. A liberdade de expressão e o problema do "Hate Speech". In: SARMENTO, Daniel (Org.). Livres e Iguais. Estudos de Direito Constitucional. Rio de Janeiro: Lumen Juris, 2006.

SARMENTO, Daniel. Comentários ao artigo 5, IV, CF. In: CANOTILHO, José Joaquim Gomes et al. (Org.). Comentários à Constituição do Brasil. São Paulo: Saraiva; Almedina, 2013. p. 252-259.

SILVA, José Afonso da. Curso de direito constitucional positivo. 28. ed. rev. e atual. São Paulo: Malheiros, 2007.

VIVES ANTÓN, Tomás S. Fundamentos del Sistema Penal: Acción Significativa y Derechos Constitucionales. 2. ed. Valencia: Tirant lo Blanch, 2011.

WEINGARTNER NETO, Jayme. Honra, Privacidade e Liberdade de Imprensa. Uma pauta de justificação penal. Porto Alegre: Livraria do Advogado, 2002.

WEINGARTNER NETO, Jayme. Liberdade religiosa na Constituição: fundamentalismo, pluralismo, crenças, cultos. Porto Alegre: Livraria do Advogado, 2007.

WEINGARTNER NETO, Jayme. Na exasperação das ruas, a luta por direitos à sombra da repressão penal. In: ENCONTRO INTERNACIONAL DO CONPEDI - DIREITOS HUMANOS, CONSTITUCIONALISMO E DEMOCRACIA NA AMÉRICA LATINA E CARIBE, 6., 2017, Costa Rica. Anais... Costa Rica, 2017.

Data da submissão: 20 nov. 2017. Avaliado em: 22 nov. 2017 (AVALIADOR A) Avaliado em: 22 nov. 2017 (AVALIADOR B) Avaliado em: 22 nov. 2017 (AVALIADOR C) Avaliado em: 22 nov. 2017 (AVALIADOR D) Avaliado em: 30 nov. 2017 (AVALIADOR E) Aceito em: 08 dez. 2017. 